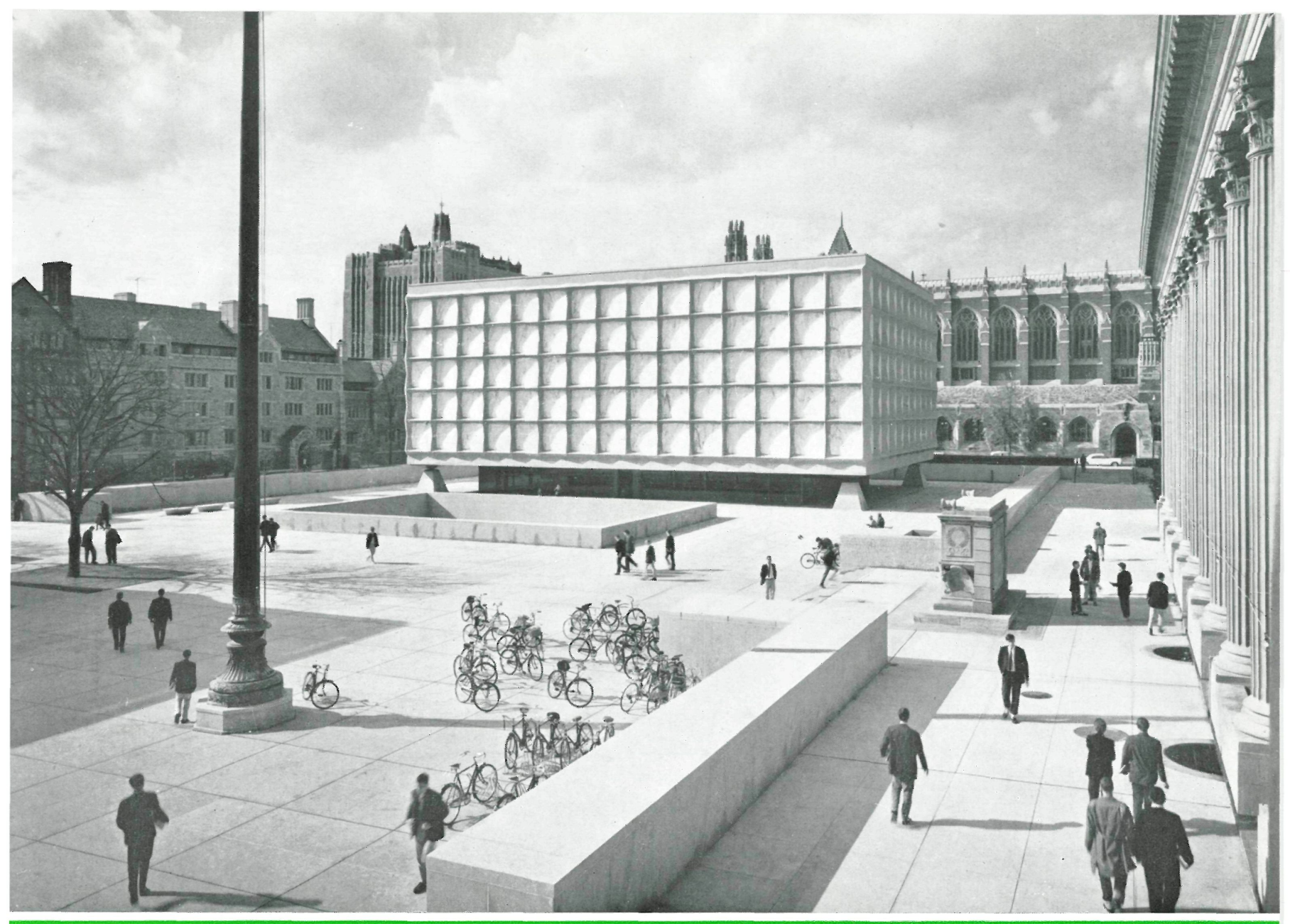

\section{Sin opesis}

Dentro del gran salón de exposiciones que contiene este nuevo y original edificio de la Universidad de Yale, se encuentra organizada una Biblioteca, de seis plantas, en la que se guardan más de $\mathbf{1 8 0 . 0 0 0}$ volúmenes y manuscritos valiosísimos.

Debajo de este pabellón se halla el centro neurálgico de investigación y funcionamiento de la Biblioteca, en el que se distribuyen: un despacho para el control central; oficinas; salas de trabajo; salas de lectura; seminarios; etcétera.

En el sótano está el almacén de libros, con capacidad aproximada para 820.000 volúmenes.

Su espectacular estructura y los cerramientos de ónice de sus fachadas prestan al edificio un brillante aspecto tanto de noche como de día, en cuanto a plástica e

iluminación.

\section{bilbliotecen de libros raros, en Yale - U. S. A.}

SKIDMORE, OWINGS \& MERRILL, arquitectos

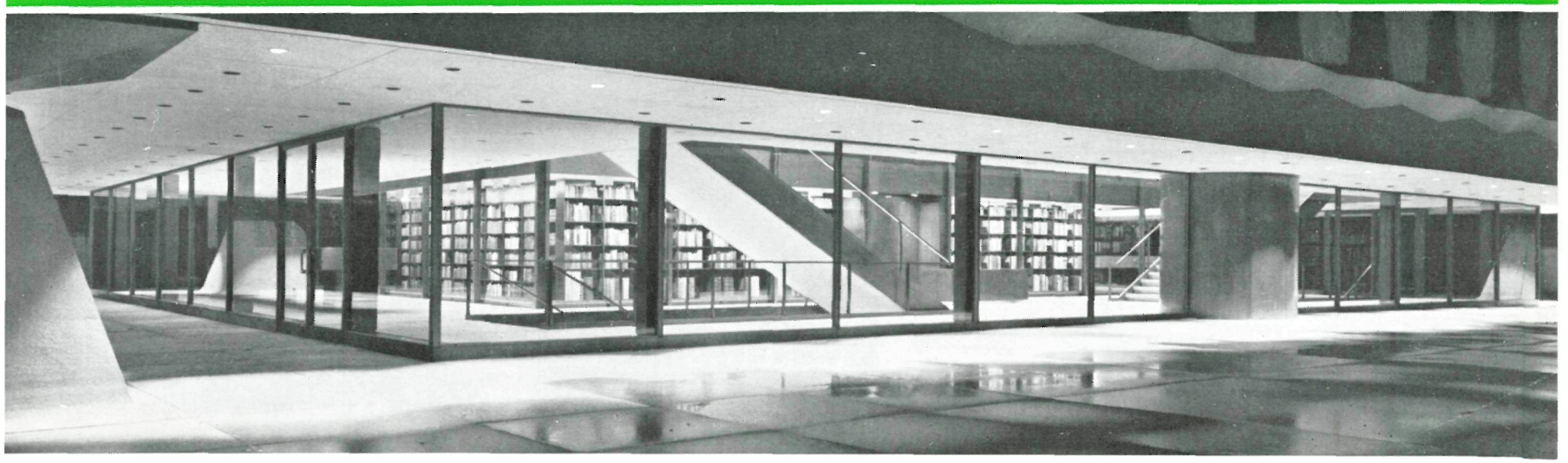




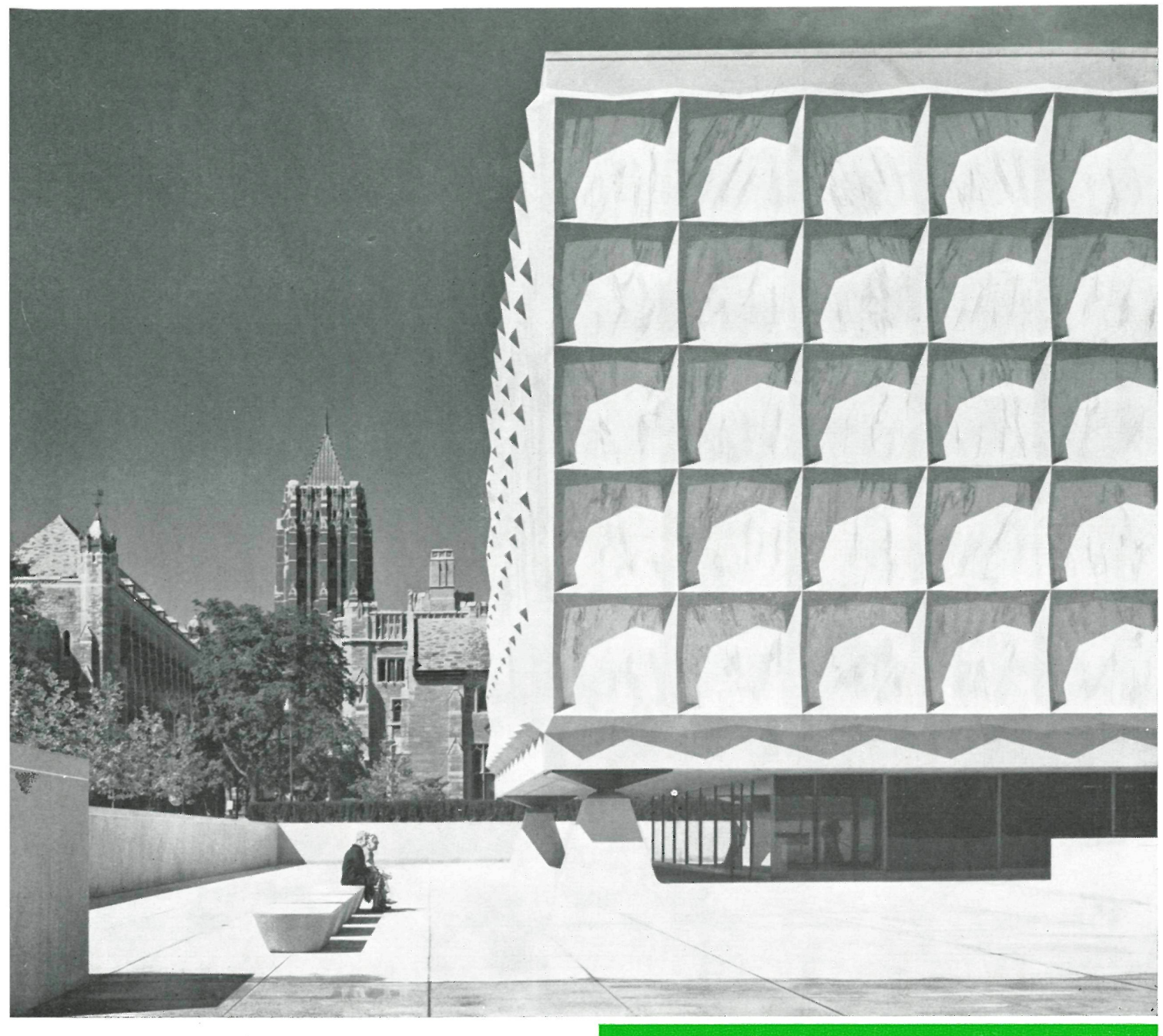

Sobre el solar ocupado por seis antiguos edificios, sito en la confluencia de New Haven's Wall y High Streets, en la Universidad de Yale, New Haven, Estados Unidos, ha sido construida esta original y elegante Biblioteca, uno de los más atractivos edificios que hayan adornado el famoso Campus universitario.

La estructura de sus muros exteriores consta de cuatro vigas metálicas tipo Vierendeel, de $15,24 \mathrm{~m}$ de altura y 40,12 m de longitud, en las que los espacios huecos han sido cuajados con paneles translúcidos de ónice; dichas vigas descansan sobre los cuatro pilares de las esquinas, que han sido acabados con gran minuciosidad.

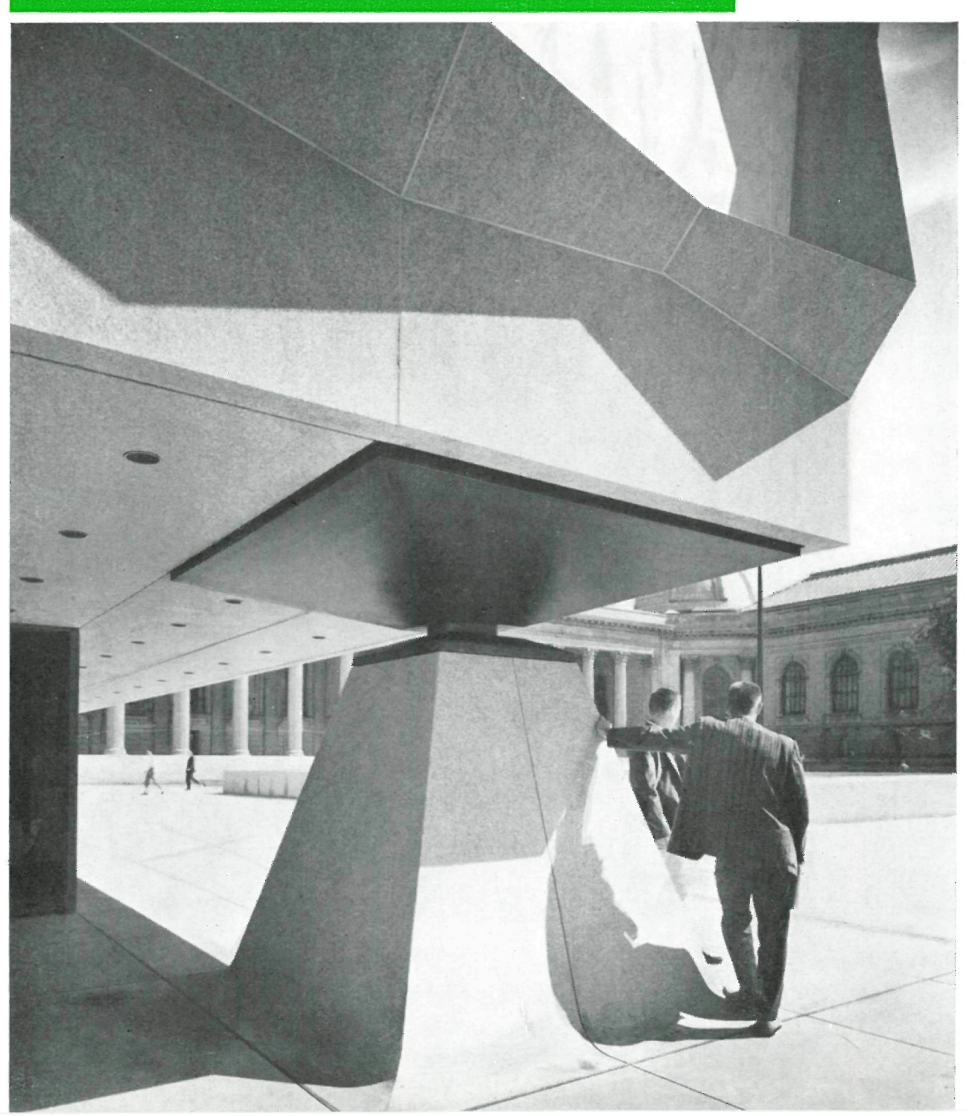


Dentro del gran Salón de Exposiciones así delimitado se encuentra organizada una Biblioteca, de seis plantas, con más de 180.000 volúmenes.

Una espectacular bóveda de vidrio, con un sistema especial de acondicionamiento de aire para proteger libros, valorados, algunos de ellos, en más de 10.500 .000 pesetas, contribuye a proporcionar una iluminación agradable y a transmitir su amplia gama de valores a los visitantes de las plantas inferiores.

Debajo de este pabellón está el foco neurálgico de funcionamiento de la
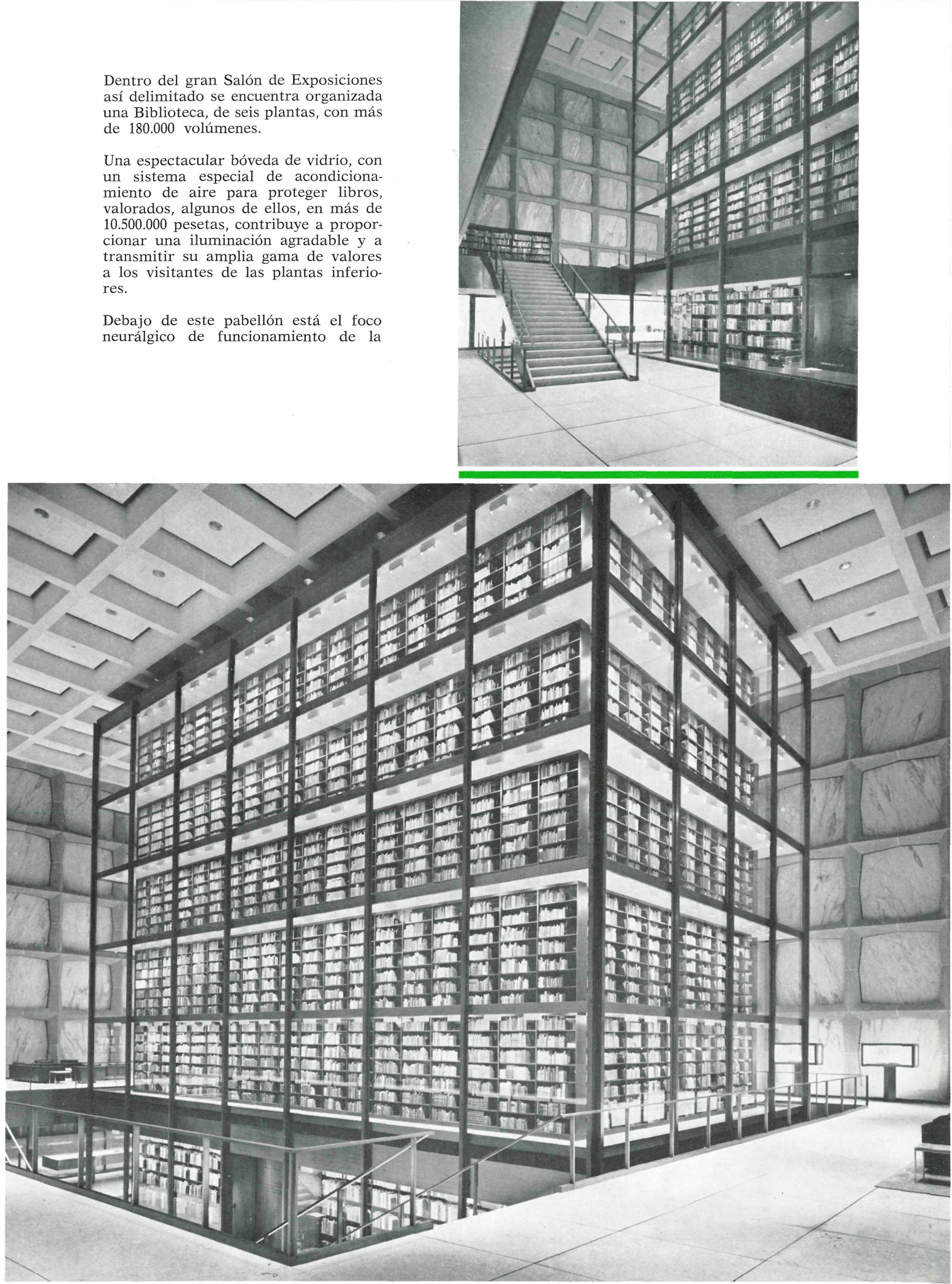
Biblioteca: un centro de investigaciones en el que se encuentra un despacho para el control central, oficinas, salas de trabajo, salas de lectura y seminarios; todo ello dispuesto alrededor de un patio central adornado con diversas formas escultóricas.

En el sótano están los servicios de almacén de libros, con una capacidad aproximada para albergar 820.000 volúmenes.

Todas las plantas se hallan comunicadas entre sí y con el almacén, no sólo por las comunicaciones verticales normales, sino también por medio de ascensores y montacargas para libros.

Existe asimismo una comunicación entre el edificio y la Biblioteca principal de Yale - la Sterling Library, situada al otro lado de la callepor medio de un túnel de paso y un sistema de tubos neumáticos.

La solución adoptada para los elementos de cerramiento de las fachadas facilita la protección de libros raros y valiosos contra la acción directa de los rayos solares; pero como en cada uno de los huecos de la celosía de las vigas han sido colocados elementos translúcidos de ónice, éstos permiten que, a su través, penetre la suficiente iluminación al interior, inundándolo con un cálido resplandor durante el día.

Durante la noche, por el contrario, el edificio emite al exterior un suave resplandor procedente de su propia iluminación, que lo hace refulgir, tal y como si se tratara de una gigantesca linterna de piedra.

Traducido y adaptado por J. M. Rubio.
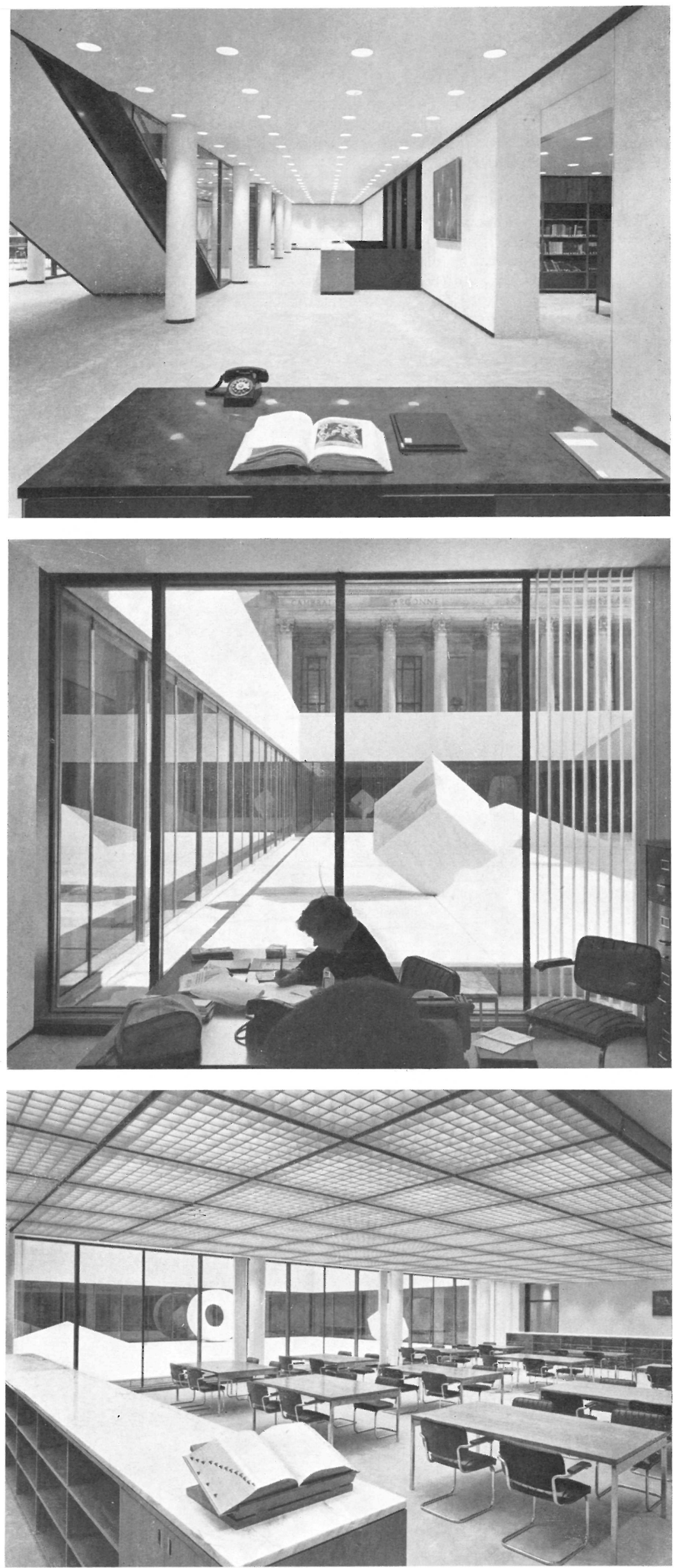


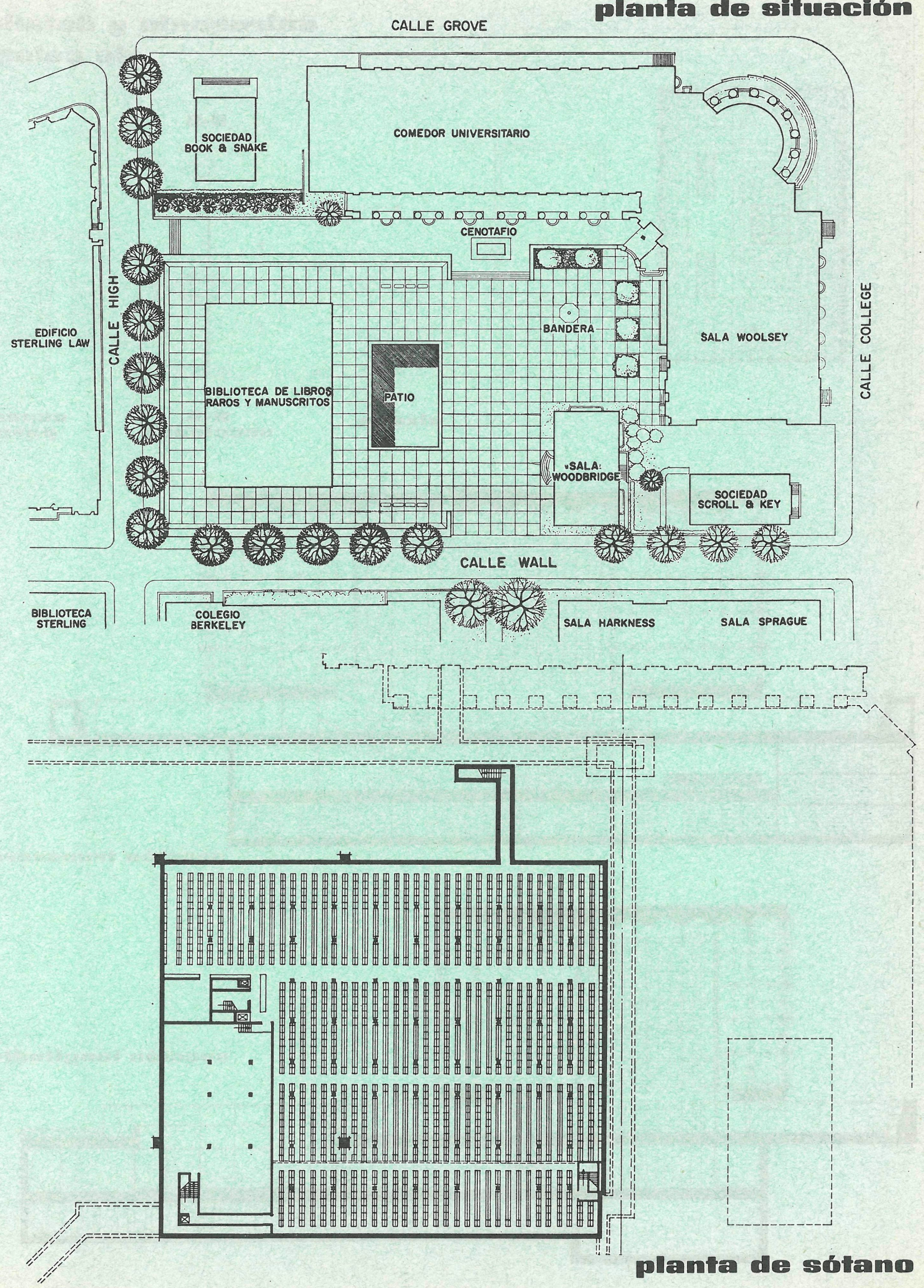




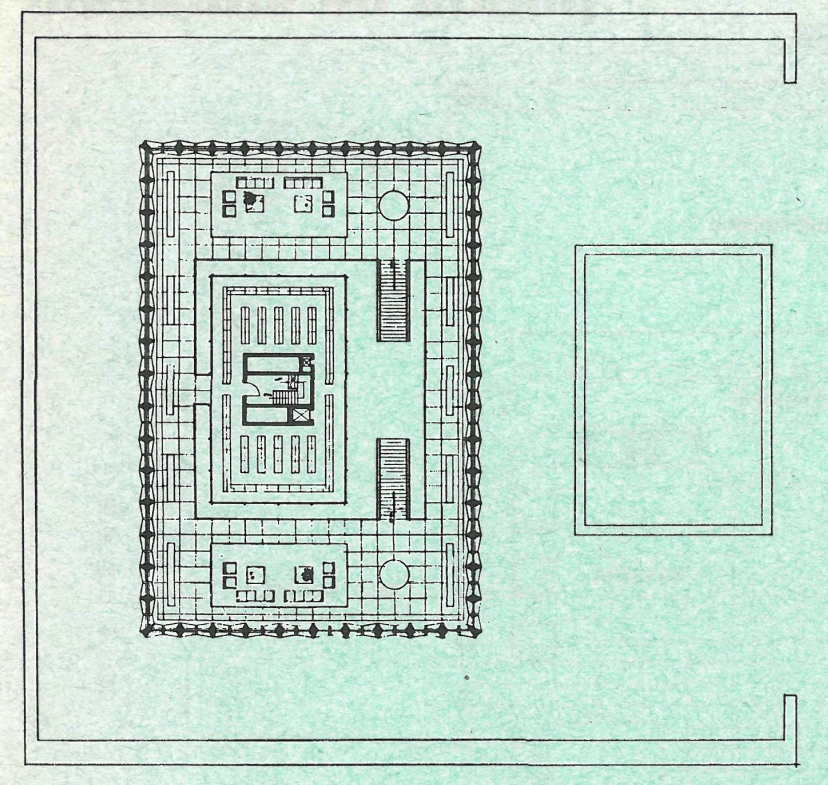

\section{entresuelo y detalles de celosía}
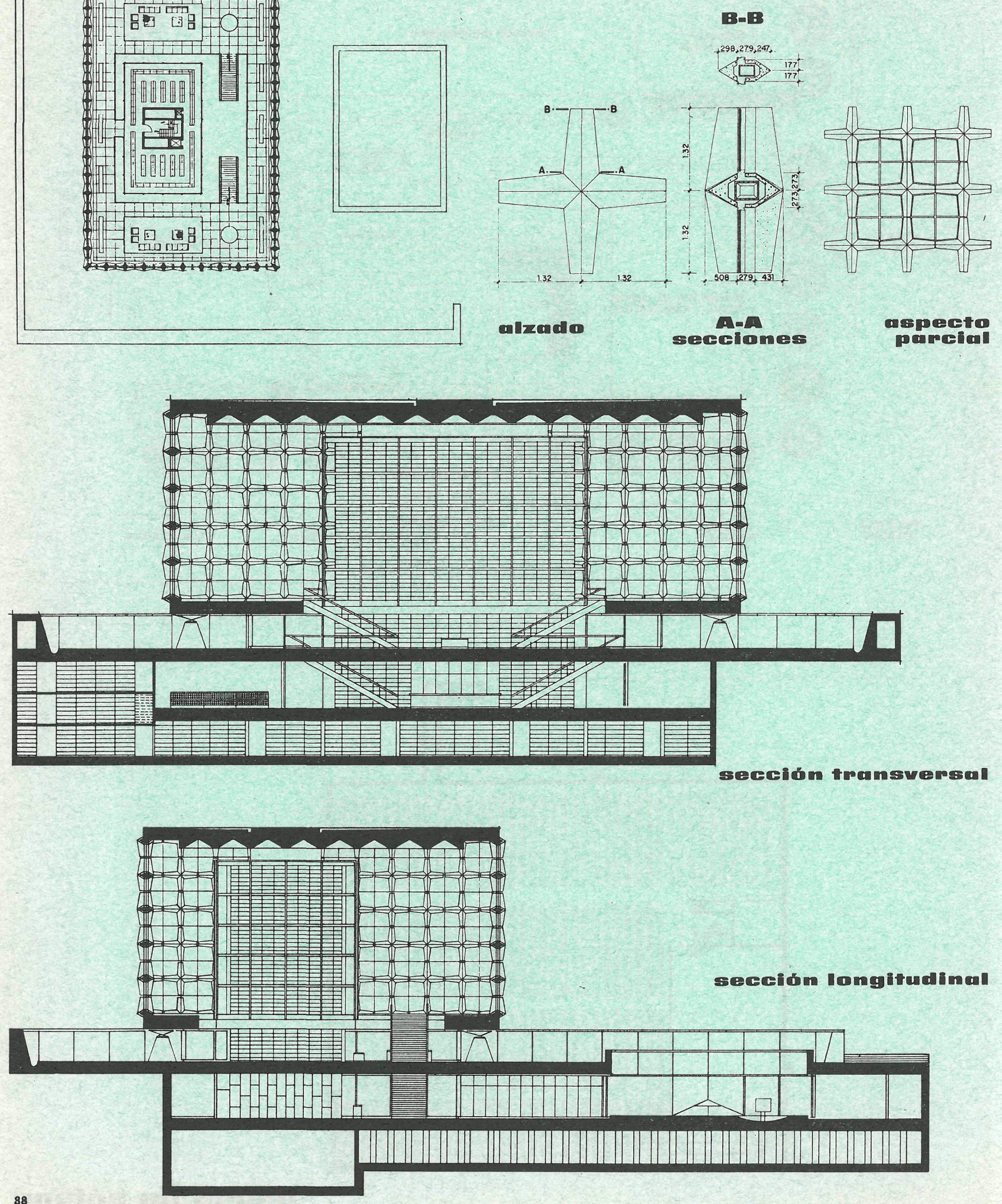


\section{Bibliothèque de livpes mapes à Yale, U.S.A.}

Skidmore, Owings et Merrill, architectes

Dans le grand salon d'expositions de ce nouveau et original édifice de l'Université de Yale, a été organisée une bibliothèque de six étages, où sont gardés plus de 180.000 volumes et manuscrits de grande valeur.

Sous ce pavillon se trouve le centre névralgique de recherche et de fonctionnement de la bibliothèque, qui comprend: un bureau pour le contrôle central, les salles de travail, les salles de lecture, les séminaires, etc.

Le sous-sol héberge le magasin de livres qui peut contenir 820.000 volumes environ.

Sa structure spectaculaire et les murs en onyx de ses façades donnent à cet édifice un aspect brillant, tant de nuit que de jour.

\section{Librumg of special editions at Yale, U.S.A.}

Skidmore, Owings and Merrill, architects

In the new and original great exhibition hall for Yale University, a library, organised on six levels, has been provided to accommodate $\mathbf{1 8 0 . 0 0 0}$ highly valuable books and manuscripts.

Below the hall there is a control centre from which the library is run: this includes control office, other offices, as well as reading and seminar rooms.

In another basement there is a book store where $\mathbf{8 2 0 . 0 0 0}$ additional books can be kept.

The structure of this building is spectacular, and its enclosing materials are beautiful and of extremely shiny appearance, both by night and day.

\section{Die Bibliothek seltemer Bucher der Yale Univemsität = U. S. A.}

Skidmore, Owings und Merrill, Architekten

Innerhalb des Ausstellungsraums, der in diesem neuen und originellen Gebäude der Yale Universität untergebracht ist, befindet sich eine sechsgeschossige Bibliothek mit 180.000 Bänden und wertvollen Manuskripten.

Unterhalb dieses Pavillons liegt das Forschungs- und Verwaltungszentrum der Bibliothek, in dem u. a. ein zentrales Kontrollbüro, sonstige Büroräume, Arbeits- und Lesesäle, Seminare usw. untergebracht sind.

Im Keller befindet sich das Bücherlager mit einer Kapazität von 820.000 Bänden.

Die aufsehenerregende Bauform und die Onyxumschliessungen der Fassaden verleihen dem Gebäude inbezug auf Form und Beleuchtung bei Tag und Nacht ein spektakuläres Aussehen. 